
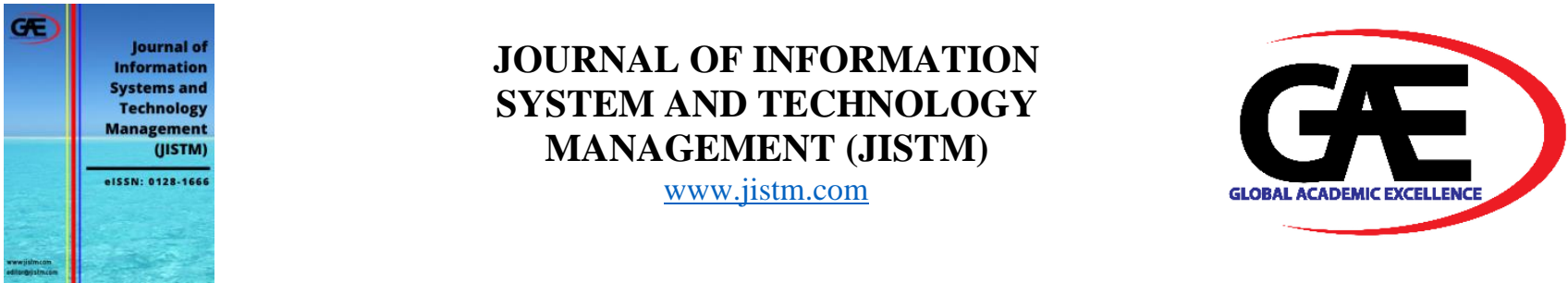

\title{
MALAYSIAN UNIVERSITY STUDENTS' TECHNOLOGY USAGE EXPERIENCE IN THE ONGOING COVID-19 PANDEMIC
}

\author{
Siew-Mun $\mathrm{Ang}^{1 *}$, Siew-Ching Ang ${ }^{2}$ \\ 1 Department of Journalism, Universiti Tunku Abdul Rahman, Malaysia \\ Email: angsm@utar.edu.my \\ 2 The University of Texas, Austin, United States of America \\ Email: siew.ang@austin.utexas.edu \\ * Corresponding Author
}

\section{Article Info:}

\section{Article history:}

Received date: 11.04.2021

Revised date: 15.07.2021

Accepted date: 07.09.2021

Published date: 14.09.2021

\section{To cite this document:}

Ang, S. M., \& Ang, S. C. (2021). Malaysian University Students' Technology Usage Experience In The Ongoing Covid-19 Pandemic. Journal of Information System and Technology Management, 6 (22), 188-199.

DOI: $10.35631 / J I S T M .622015$

This work is licensed under CC BY 4.0 (a)
Abstract:

This paper examined university students' technology usage experience during the ongoing Covid-19 pandemic in Malaysia. As this crisis continues into its third year, universities and schools across the world have had to close their campuses and adopt new norms of teaching-and-learning. What are some of the problems which students had encountered during their online teaching-andlearning (OTL) sessions or classes? In this study, the authors had surveyed eighty-five students from a local university, located in the mid-northern region of Malaysia. The study had used convenience sampling and an online survey form which was distributed via WhatsApp and emails. It was a quantitative study. The main findings include that a majority $(88.2 \%)$ of the students reported using a combination of laptops and other devices, such as smartphones and home desktops. Moreover, one in four of them had shared their devices with their parents or siblings. In addition, slightly over half $(51.8 \%)$ of the students surveyed reported difficulties with Internet access during their classes. The issues they cited mainly revolved around 'poor internet connection' and 'unstable connection'. As a result, students were sometimes unable to respond to their lecturers' questions in class or enter classes late due to Internet lagging issues. This showed that while the technology penetration rate is reasonably high among the students, their access to stable Internet bandwidth and connection remains a challenge and a problem. The authors concluded that the Malaysian government should continue to improve the country's Internet speed and digital infrastructure while taking steps to narrow the pre-existing digital gap between the country's haves and have-nots.

\section{Keywords:}

Technology Usage, University Students, Covid-19 Pandemic, Online Teaching-and-Learning (OTL), Internet Access, and Digital Gap 


\section{Introduction}

DOI: 10.35631/JISTM.622015

Technology helps to advance human civilizations and computer technology is yet another leap in our technological innovation which has revolutionized the way we communicate, live, work, study, and get medical assistance.

In the Modernization Theory as outlined by Walt Rostow (1960, 1978), the five-stage (i.e., (traditional stage, transitional stage, take-off stage, drive to maturity stage and high mass consumption stage) technological adoption are important criteria for a country's industrialization and development (as cited in Macionis, 2015). This is despite criticisms of this Theory as an inadequate model explaining development (Jacobs, 2020). It is still believed that technological advancement can be an impetus for economic growth. Therefore, Malaysia is keeping abreast with technological innovations in hopes that these would help power its economy and prosperity as well as growth.

Has Malaysia's digitalization process been successful? According to the 2018 Internet Users Survey (henceforth, the 2018 IUS) conducted by the Malaysian Communications and Multimedia Commission (MCMC), the percentage of Internet users at the national level has increased from $76.9 \%$ in 2016 to $87.4 \%$ in 2018 (MCMC, 2018). While this high percentage looks very impressive, news published in Malaysiakini, a local web-based news portal, suggested that the situation on the ground was not as rosy as the statistics showed. For example, during this Covid-19 pandemic, vulnerable groups such as children of the Orang Asli and the Bottom 40 percent (or B40) group have been reported to be missing out on education because they either lacked adequate Internet access or technological devices to attend online classes (Halim, 2021; Ghazali, 2021; Malaysiakini, 2021).

Meanwhile, the Covid-19, an infectious disease caused by the SARS-CoV-2 virus, has caused a global lockdown. Thanks to the help of the Internet, the classroom was moved from the physical to a virtual environment. In Malaysia, the government had instituted the Movement Control Order (MCO) 1.0 on $18^{\text {th }}$ March 2020 and variations of the MCO since then. The MCO 2.0 and the MCO 3.0 were later imposed in stages on all states (with varying different orders depending on the infection rates in each state) due to a resurgence in the Covid-19 cases. As the result of such resurgence of Covid-19 cases in the country, online classes at schools and universities in Malaysia have been on-going without fail since $18^{\text {th }}$ March 2020.

In view of the sudden need for online or digital classes in Malaysia, the authors have conducted a preliminary survey on university students' technology usage experience. This is because academics and students alike have had to adopt (at a short notice) to new norms of teachingand-learning online as well as work and/or study from home. This new technological adoption using digital platforms, born out of need, is part and parcel of the digital megatrend or revolution which is sweeping across the world (Schwab, 2016).

\section{Literature Review}

There is much literature on the Malaysian government's efforts in encouraging Internet usage among its citizens and in helping the underprivileged gain this access.

\section{Broadband and Internet Access}

According to the 2018 IUS conducted by the MCMC, a total of 4,160 Internet users responded to its survey. It was found that nine $(93.1 \%)$ out of 10 Internet users had used a smartphone to 
access the cyberworld. Moreover, WhatsApp and Facebook were the most well-liked communication platform and social media respectively. It's also reported that the Malaysian government via its 2010 National Broadband Initiative has made continuous efforts to reduce the price of Internet packages in the country and increase the speed of fixed broadband. These efforts have contributed to the rise of Internet users in the country.

Moreover, the 2018 IUS found that Malaysian users $(\mathrm{N}=3,686,88.6 \%)$ mainly accessed the Internet from the comforts of their homes, followed by access on-the-go $(\mathrm{N}=2,833,68.1 \%)$ and workplace access $(\mathrm{N}=2,346,56.4 \%)$. Accessing free wi-fi anywhere and everywhere was not as popular in 2018 as it was in 2016 . The report attributed this decline to the easy availability of good-value-for-money mobile Internet data plans provided by telecommunications service providers in Malaysia. Therefore, users had chosen to buy their own mobile data plans rather than to search for and relying on free wi-fi.

\section{Impact of Covid-19 on the Education sector}

The Covid-19 pandemic has had a serious impact on the education sector, and in fact, on all aspects of life as we knew it before it began. Universities and schools have had to close their campuses and the students' learning environment has been confined to their respective homes.

In an OECD report, Schleicher (2020) had outlined the popularity of online platforms to ensure that learning continued for students. Moreover, students could explore more lessons at their own pace using pre-existing online content. Schleicher (2020) also stated that teachers reported a higher need for training on the use of Information and Communication Technologies (ICT).

\section{Technologies in Education}

According to Raja and Nagasubramani (2018), technological innovations have revolutionized the education sector and their uses have made teaching-and-learning more enjoyable for all concerned. They had outlined how students can make use of computer technology to enhance their own learning such as using the Internet round the clock and acquiring online degrees from top institutions of higher learning. However, the authors cited Gressard and Loyd (1985) who asserted that teachers' attitudes towards computers are a major factor in determining the efficacious execution of ICT in education. Moreover, Shampa Iftakhar (2016) mentioned how improvements in teachers' skills and expertise in using ICT are the key factor in enabling the incorporation of technology in education.

On the other hand, technologies in education can cut both ways, i.e., by either overcoming or aggravating existing social inequalities depending on the course design, and who have access to them (MIT, n.d.). Online-only courses are found to lower students' academic performance compared to in-person, face-to-face classes (MIT, n.d.). Nonetheless, students performed as well in courses with a combination of both face-to-face and online components compared to traditional in-person classes (MIT, n.d.).

\section{Problems with OTL}

Amar Singh (2021) commented on the impact of the Covid-19 pandemic on poor children. According to him, the pandemic has exacerbated the divide between the wealthy and the underprivileged as well as widening the digital gap between the haves and the have-nots. For example, school shutdowns have resulted in some children missing out on education and retrogressing in learning aptitudes. Moreover, a Ministry of Education survey in March-April 
2020 indicated that 37 percent of children did not have any digital device. Only 15 percent of the students had personal computers while half had relied on smartphones to attend virtual classes.

Moreover, the Malaysian National News Agency (BERNAMA) reported that laptops priced at RM2,000 and below were sold out in Ipoh, Perak following the implementation of home-based OTL for school children (as cited in Free Malaysia Today, 2021; The Star, 2021). However, it was thought that the Ministry of Education's Educational TV programme named as DidikTV $K P M$ was a good solution to overcoming access problems related to OTL in the country (BERNAMA, 2021), especially for rural areas.

In a study conducted by Bahar, Wahab, and Ahmad (2020), instructors from both public and private universities were found to have faced some problems and challenges in conducting online teaching-and-learning (OTL). For example, technology incompetence and the lack of interactivity between instructors and students. However, students' technology usage experience and the problems they encountered during OTL were not part of their study.

\section{Research Method}

This exploratory study was a quantitative research using an online survey. A total of 85 students from a local university, located in the mid-northern region of Malaysia, were asked about their technology usage experience while attending virtual lectures and tutorials during their January 2020 and May 2020 semesters when the country was still in the Covid-19 pandemic lockdown and then partial lockdown. The data collection was conducted via convenience sampling which was disseminated via emails and WhatsApp.

\section{Problem Statement}

Little is known about university students' technology usage experience while attending virtual classes. This pilot study explores three themes:

A) Location of Internet Access: from where did they access the Internet?

B) Access to Device: what device - computer/laptop/smartphone/tablet - did they use?

C) Wi-Fi and Internet Speed: were the internet velocity and bandwidth enough to support everyone's usage?

\section{Results and Discussion}

\section{Location of Internet Access}

Question 1. When asked where they had stayed during the MCO 1.0, sixty-four $(75.3 \%)$ respondents had replied that they had stayed in their own respective hometowns. Only twenty $(23.5 \%)$ respondents had stayed behind in the university town and only one (1.2\%) respondent had stayed somewhere 'other than hometown' (See Figure 1). All but one respondent surveyed were locals. 


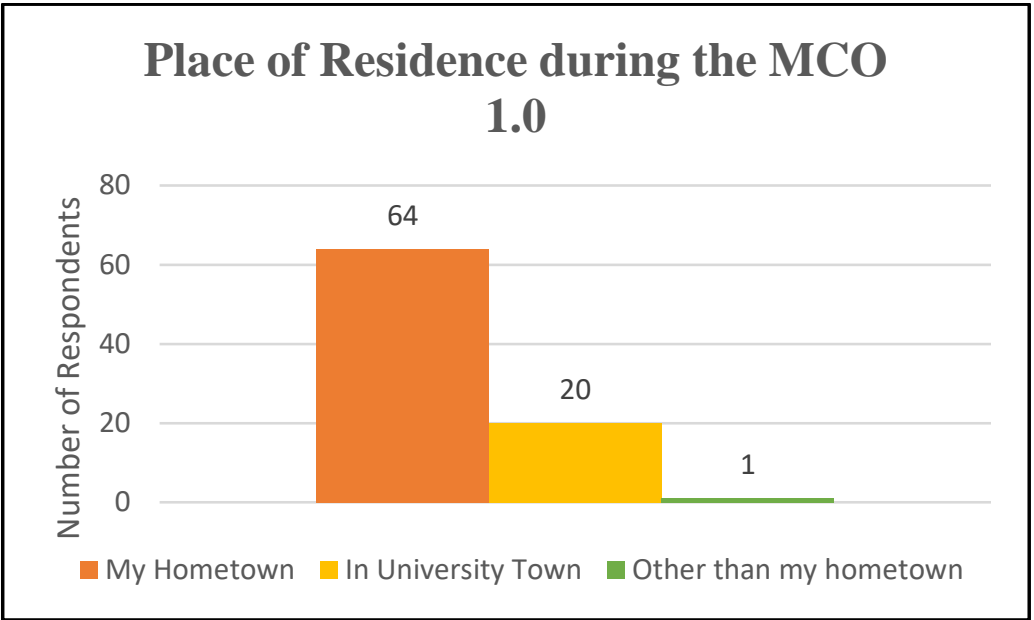

Figure 1: Respondents' Residence during the MCO 1.0

Question 2. Respondents were then asked why they had stayed in the residence they had mentioned in the first question. For this, the respondents were asked to provide multiple reasons for their decision and the following (Figure 2) is the breakdown of their answers, in numbers and percentages.

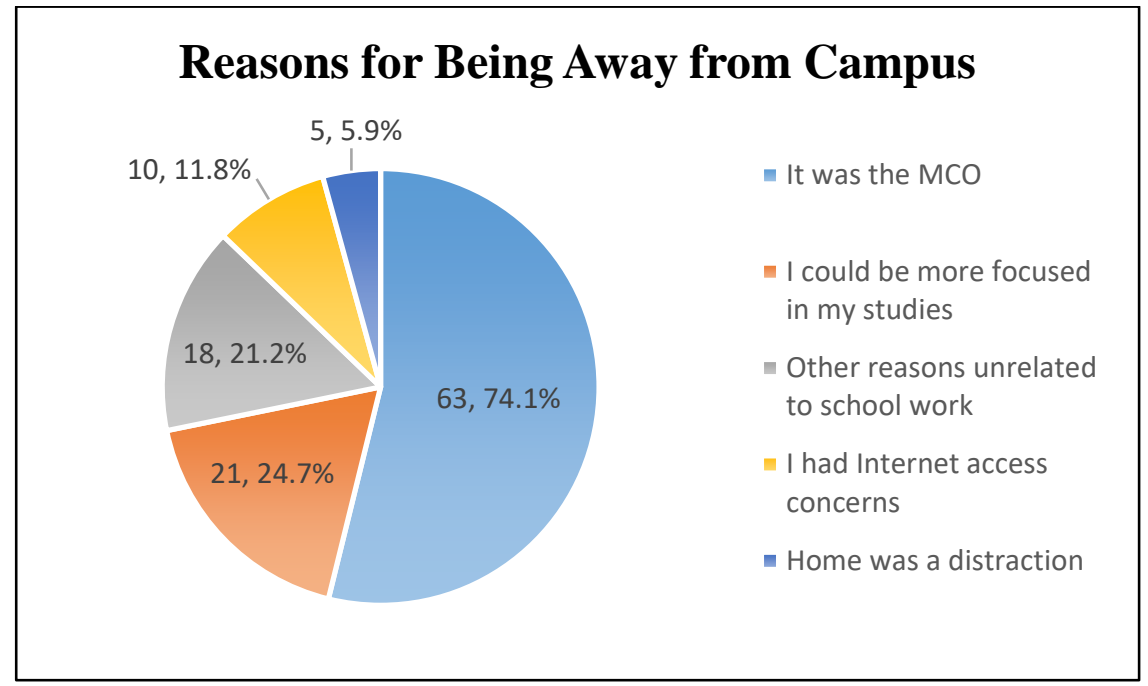

Figure 2: Reasons for Staying in Their Hometowns or in University Town or Elsewhere

As can be seen from Figure 2, there were indeed respondents who were concerned about Internet connectivity issues in their own hometowns and that's why they had stayed on in the university town even though the place became quite deserted after MCO 1.0 was enforced. Moreover, internet availability issues were especially acute in rural areas of Malaysia. In Sabah, there were news reports about an 18-year-old student, Veveonah Mosibin, from Universiti Malaysia Sabah (UMS) who, on at least two occasions, had had to climb a tree to get stable 3G Internet connection to sit for her university's online exams (Malaysian Wireless, 2020; Lee, 2020; Tan, 2020). She even resorted to staying overnight on a langsat fruit tree for her online exams (Lee, 2020). Moreover, due to her village being in a remote part of Sabah, she didn't have access to any good mobile data plans at home either (Malaysian Wireless, 2020). This showed that Internet connectivity is better in the country's urban areas and that the digitalization process in Malaysia is still ongoing and could be even better in the future. 
From Figure 2, it is also noted that one respondent had probably answered contradictorily in Question 1 and Question 2 of the survey; only 63 respondents and not 64 mentioned that they had stayed in their hometowns because it was the MCO. Conversely, there were 21 respondents and not 20 who had cited 'I could be more focused in my studies'; this meant that they had stayed put in the university town.

The digital gap between the haves and the have-nots can probably be bridged because there is much awareness of this issue and efforts are being made within the Malaysian government to help its citizens adopt ICT into their lives. For example, the government has initiated 1NITA project led by women entrepreneurs for ICT adoption in their small-and-medium-sized enterprises (SMEs), established Internet centres in rural areas and low-income residential areas, set up Wi-Fi 'hotspot' areas within the city of Kuala Lumpur, enabled a One-Stop Business Registration and Licensing Portal (or also known as Malaysiabiz Portal) and expanded ICT infrastructure into the rural areas via the Rural Internet Telecentres (PID) (MAMPU, 2019). These initiatives are ways in which the Malaysian government had planned to bridge the digital divide in the country. Have these initiatives worked well? Only further research can assess the effectiveness of such programmes on the ground.

\section{Access to Device}

Question 3. When asked if they have had to share their device with others, 67 respondents (78.8\%) said that they did not need to share it with anyone. The following graph (Figure 3) showed the breakdown of those who did not need to share and those who have had to share their device with others; with six respondents (7.1\%) saying that they have had to share with one person other than themselves, another six respondents $(7.1 \%)$ who said that they have had to share with two persons other than themselves and finally, two respondents $(2.4 \%)$ who said that they have had to share their device with three or more people. Four respondents $(4.7 \%)$ had declined to answer this question.

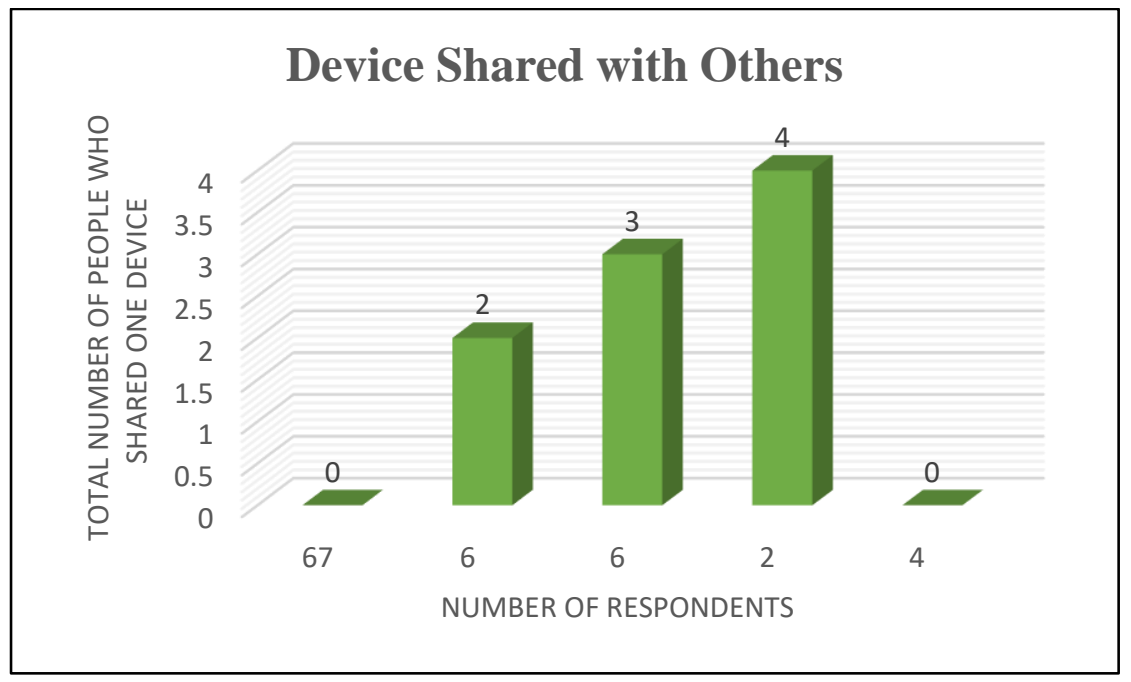

Figure 3: Those Who Shared Their Device with Others and Those Who Did Not

On a positive note, a big majority of the respondents have enjoyed good fortune and prosperity because they did not have to share their device with anyone. They and their parents were also probably the ones who have heeded the Malaysian government's call to learn and adopt ICT into their lives. As such, when the Covid-19 pandemic hit our shores, the respondents were Copyright $\odot$ GLOBAL ACADEMIC EXCELLENCE (M) SDN BHD - All rights reserved 
able to adapt quickly and attend their university's virtual classes without much hassle. Another possible reason which explained the respondents' high ICT adoption rate was the pressure to conform to group norms. Peers, as one of the basic agents of socialization, are important in establishing group norms and conformity within the university as proven in pioneering experiments on conformity by Muzafer Sherif and Solomon Asch (Chang, 2015; Macionis, 2015). The need and pressure to conform to group norms meant that the respondents had, even in pre-Covid-19 days, already bought smartphones and other digital devices to keep up with their peers.

Furthermore, ICT adoption is also part of Malaysia's digital agenda and strategy. For example, the Malaysia Digital Economy Corporation Sdn Bhd (MDEC) has outlined several strategic thrusts to propel the nation's economy forward (MDEC, 2019). It helps Malaysian businesses and youths to digitally transform themselves. For example, through e-Rezeki, youths, especially those from the B40 group, can find employment by completing micro tasks and digitally enabled tasks or jobs (MDEC, 2019). It also has an eCommerce platform where both the youths and the veterans are taught to embrace e-commerce in their businesses while its Global Online Workforce (GLOW) programme teach and empower Malaysians to earn income online professionally, either based at home or at a location of their choice (MDEC, 2019).

Question 4. Respondents were further asked whom they had shared their device with, to which 64 respondents $(75.3 \%)$ replied 'not relevant', 15 respondents $(17.7 \%)$ replied 'my sibling(s)', two respondents $(2.4 \%)$ said 'my parent(s)' and four respondents $(4.7 \%)$ did not answer the question. Here, a discrepancy was again discovered in the respondents' answer where those who said that they had shared their device totalled 17 respondents as opposed to only 14 respondents in Question 3. This could mean that the respondents were more honest when asked a direct question like 'I shared my device with...' On the other hand, both questions 3 and 4 can be said to be a check-and-balance in ensuring that accurate answers were given by the respondents.

Question 5. Finally, the respondents were asked about the devices they used to attend their virtual or online classes. They were asked to tick all relevant devices used. Figure 4 (below) showed the breakdown in numbers and percentages.

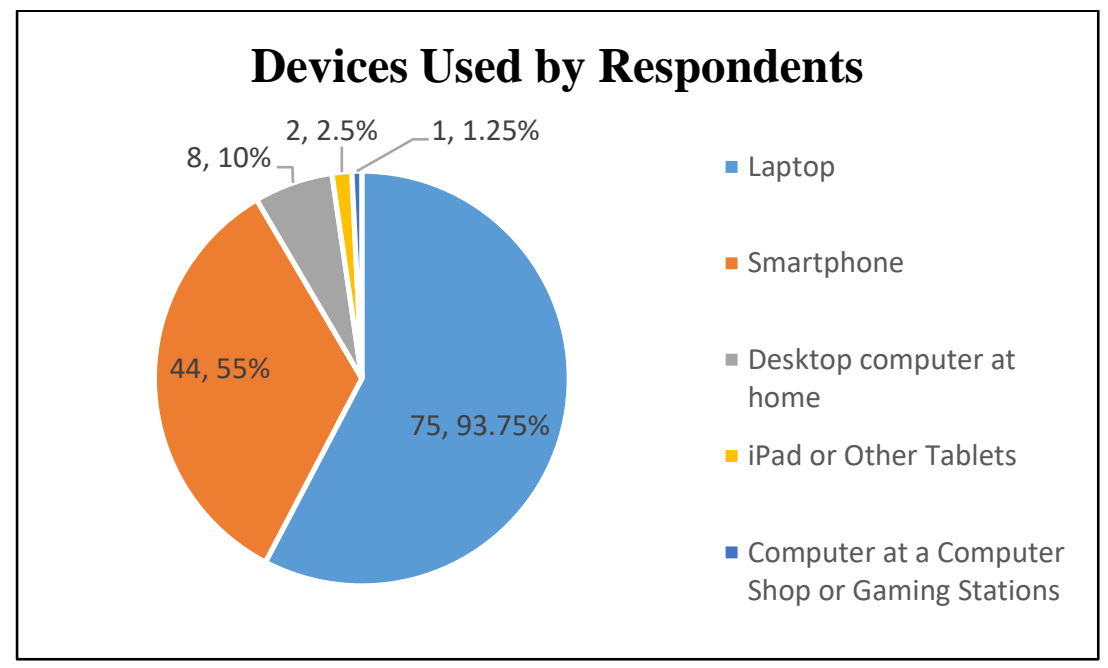

Figure 4: The Devices Used by The Respondents to Attend Online Classes 
From Figure 4, a big majority of the respondents had used a combination of devices to attend their online classes, with laptops $(\mathrm{N}=75,93.8 \%)$ and smartphones $(\mathrm{N}=44,55 \%)$ topping the charts. A small number of respondents $(\mathrm{N}=8,10 \%)$ had used the desktop computer at home while yet others had used the iPad or other tablets $(\mathrm{N}=2,2.5 \%)$ and one respondent $(1.3 \%)$ had used a computer at a computer shop or gaming station. This paper's finding slightly differed from MCMC's 2018 IUS findings (as elaborated in the Literature Review section above). For example, the 2018 IUS had found that nine $(93.1 \%)$ out of 10 Internet users had used a smartphone to access the cyberworld whereas in this survey, many respondents had used a combination of devices.

On the surface, this study's respondents seemed more privileged with their laptop usage while others could only afford to use the smartphone to access the Internet and to attend virtual classes. Further and future probing by the authors would reveal more information such as the cost of the respondents' respective laptops and smartphones. Generally, the students from this mid-northern university who were surveyed are in either the M40 or the B40 income groups. Only a very small number of them could be in the T20 income households.

Overall, an affordable smartphone is as cheap as a laptop in today's Malaysia. For example, the cheapest laptop in the market featured on a Malaysian website by iPrice Group Sdn Bhd, is a DELL Latitude E6230 at only RM899 (iPrice, 2021). Using the same amount of money, one could choose to buy a smartphone instead, such as a Vivo V20 priced at RM899 (iPrice, 2021) or an Apple iPhone 6 Plus, priced at RM650 (iPrice, 2021) with some extra left as savings.

To bridge the digital gap and to enable continuous OTL, the Ministry of Higher Education (MOHE), Malaysia, has announced that all students in the Higher Education Institutions are eligible to apply for a special data plan package from Celcom, Digi, Maxis, and TM (Unifi Mobile), and IT device package from Acer, Samsung, and Apple Online Store (as cited in the mid-northern university's email announcement). On top of these packages, all students are also eligible to apply for a free daily 1GB data from eight telecommunications companies in the country.

Furthermore, this mid-northern university has also started its own 'Student Laptop Loan Programme' to enable its students from the B40 households to borrow a laptop for three months in the January 2021 semester. A total of 50 laptops are available for loan and each of them has an Intel Core i5 $1^{\text {st }}$ Generation or $2^{\text {nd }}$ Generation processor. Moreover, each of these 50 laptops has 4GB RAM, 120GB SSD disk space and runs on Windows 10. Besides, both staff and students from this mid-northern university have been provided with free web-based Microsoft Office 365 package to ease usage.

As a trading nation, Malaysia must keep up with technological advancements and cannot afford to live like a hermit in a globalized environment. As such, the Malaysian government has kept pace with the IR 4.0 through its digital agenda via MDEC, among many other government agencies. However, there are pros and cons of such ICT adoption. While people tend to focus on the positive aspects, the authors feel that they should also provide a balanced view of such progress. For example, the pace of life has accelerated with ICT adoption and many people expect a quick reply to their emails and WhatsApp messages. However, local culture has ameliorated this phenomenon whereby some people would consciously resist the speed and pause to think of suitable responses before replying to emails or WhatsApp. 


\section{Wi-Fi and Internet Speed}

Question 6. Over half $(\mathrm{N}=44,51.8 \%)$ of the respondents had experienced difficulties with their Internet access during their online classes. This was an open-ended question and the authors had found two major themes: poor Internet connection (i.e., can't go online and once it's disconnected, it takes some time to get re-connected to the Internet) and unstable connection (i.e., lagging or stalling during their streaming). Several reasons could probably explain such difficulties. For example, since it's a nation-wide lockdown, almost everyone has had to use their Wi-Fi more intensively, therefore, causing a lag in the Internet connection. Alternatively, as the Internet packages subscribed by most of the respondents were wi-fi packages $(\mathrm{N}=73$, $85.9 \%$ ), they are less stable than wired fibre optics broadband. Finally, the country's broadband infrastructure must continuously improve so that Malaysian citizens' Internet experience become seamless, and uninterrupted.

Question 7. When asked when they had experienced difficulties with their Internet connection, 37 respondents $(45.68 \%)$ cited peak hours ( $8 \mathrm{am}$ to $5 \mathrm{pm})$ while others $(\mathrm{N}=22,27.16 \%)$ cited off peak hours $(5 \mathrm{pm}$ to $11 \mathrm{pm})$ and a small number ( $\mathrm{N}=8,9.88 \%)$ cited midnight (11pm to $1 \mathrm{am})$. Those who said they didn't experience any issue totalled $32(39.51 \%)$ respondents. The respondents had been asked to pick one or more choices in this question. Figure 5 (below) summarizes the data. Moreover, in this paper, the authors had defined peak hours and off-peak hours differently from Malaysia's telecommunications companies. They have different cut-off times for peak and off-peak hours.

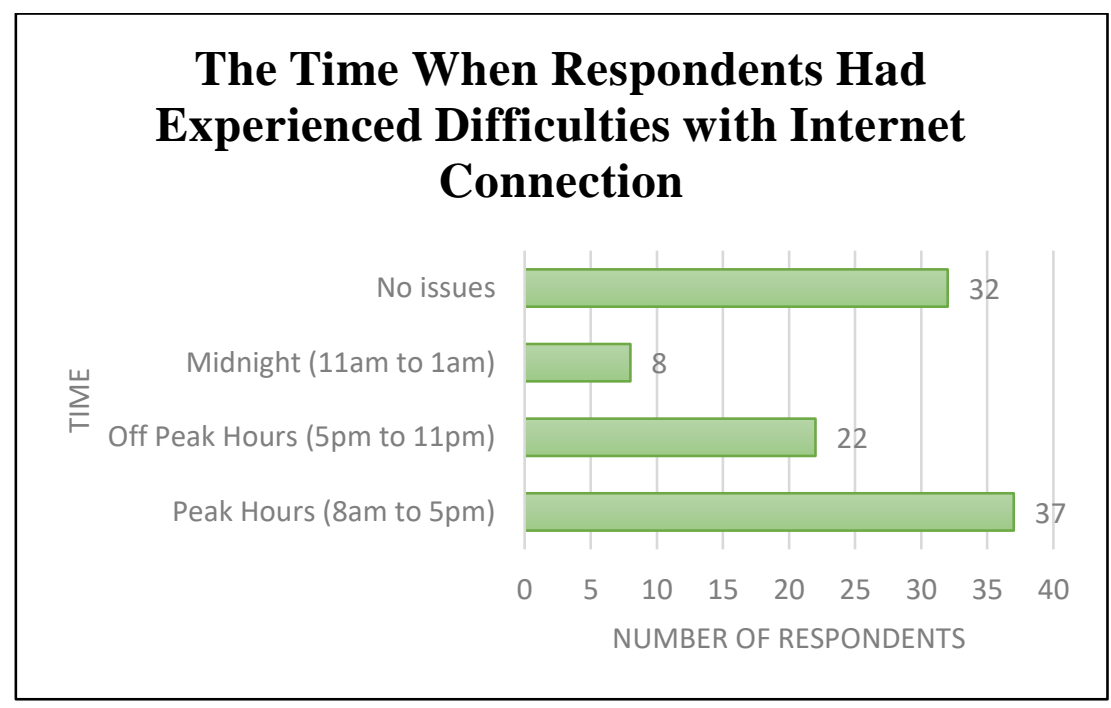

Figure 5: Time When Respondents Had Experienced Internet Connection Difficulties

\section{Conclusion}

From the results and discussion, we can safely conclude that technological or ICT adoption in education and in the country has hiccups. Over half of the respondents' technology usage experience has not been seamless and this speaks volumes about the need for Malaysia to continuously improve its connectivity infrastructure, both in the urban areas and especially in the rural areas.

In this ongoing Covid-19 pandemic, this mid-northern university's students surveyed had generally occasionally experienced Internet connectivity issues and sometimes, they could only join their classes half-way through the lessons. Some students had complained about lagging 
and they couldn't respond to their lecturers' questions. Other students were not able to interact much with their lecturers because they were using the smartphone and felt that it's inconvenient to type into the chat box using the smartphone.

The limitations of this study included not being able to generalize its findings. This is because, having conducted convenience sampling, most of the respondents was Chinese Malaysians as is reflected in this mid-northern university's overall student population. Moreover, the sample size and its ethnic composition should also be increased and diversified to reflect multi-racial Malaysia.

Future research can attempt to examine the respondents' Wi-Fi packages and their experience dealing with poor and unstable Internet connections during their online classes. Moreover, oneto-one interviews can be conducted to find out how those who had shared their devices with other family members juggle their classes and time. As it is now, due to the private and confidential nature of the questionnaire, there is no way the authors could trace those who had said that they had shared their device with their family members. This can be an interesting peek into these 17 respondents' experience and worldview on ICT adoption in education and in the country.

Finally, it can be seen from the survey results above that more than half of the tertiary students surveyed had reported that their technology usage experience had not been smooth. There have been hiccups and challenges during their OTL sessions. Therefore, it's important that Malaysia continues to improve its Internet speed and digital infrastructure, both in the urban and rural areas.

\section{References}

Amar Singh HSS. (2021, January 8). COMMENT: Covid-19 Pandemic and Its Impact on Children. Malaysiakini. Retrieved from Malaysiakini - COMMENT | Covid-19 pandemic and its impact on children

Amir Yusof. (2021, February 2). MCO Extended in All Malaysian States Except Sarawak Until Feb 18: Senior Minister Ismail Sabri. Retrieved from MCO extended in all Malaysian states except Sarawak until Feb 18: Senior minister Ismail Sabri - CNA (channelnewsasia.com)

Baase, S. (2013). A Gift of Fire: Social, Legal, and Ethical Issues for Computing Technology (4th ed.). Essex, England: Pearson Education Limited.

Bahar, N., Wahab, S.N. \& Ahmad, N.D. (2020). "Understanding Challenges Faced in Online Teaching and Learning Among Malaysian Universities' Instructors During COVID-19 Pandemic," 2020 Sixth International Conference on e-Learning (econf), pp. 154-157, doi: 10.1109/econf51404.2020.9385474.

BERNAMA. (2021, February 15). DidikTV Can Help Solve PdPR Issues - PIBGN. Retrieved from BERNAMA - DidikTV can help solve PdPR issues - PIBGN

Brown, J. (2017, October 24). 9 Ways Facebook Affects Your Mental Health (And What You Can Do). Retrieved from 9 ways Facebook affects your mental health (And what you can do) | by Jordan Brown | Medium

Chang, W. (2015, December 15). Conformity to Group Norms. Retrieved from Conformity to Group Norms. Definition | by Wesley Chang | Psychology Secrets for Marketing | Medium 
Delkic, M. \& Landry, C. (2020, May 12). Your Wednesday Briefing: India's Carbon Emissions Drop. The New York Times. Retrieved from Wuhan Tests, Modi Rescue Package, Reopenings: Your Wednesday Briefing - The New York Times (nytimes.com)

Free Malaysia Today. (2021, February 11). Laptops Priced Below RM2,000 Sold Out in Ipoh. Retrieved from Laptops priced below RM2,000 sold out in Ipoh | Free Malaysia Today (FMT)

Ghazali, F. (2021, January 28). Jakoa Ready to Support Orang Asli Students Resume Classes - DG. Malaysiakini. Retrieved from Malaysiakini - Jakoa ready to support Orang Asli students resume classes - DG

Halim, F. (2021, February 7). MP Urges Telcos to Provide 'Care Package' for Students. Malaysiakini. Retrieved from Malaysiakini - MP urges telcos to provide 'care package' for students

iPrice. (2021). Latest Laptops in Malaysia: Price List for February 2021. Retrieved from Latest Laptops Price in Malaysia | Harga Murah February, 2021 (iprice.my)

iPrice. (2021). Latest Phones \& Tablets in Malaysia: Price List for February 2021. Retrieved from Latest Phones \& Tablets Price in Malaysia | Harga Murah February, 2021 (iprice.my)

Jacobs, J. (2020, February 11). Rostow's Stages of Growth Development Model: The economist's 5 stages of economic growth are oft criticized. ThoughtCo. Retrieved from Rostow's Stages of Economic Growth and Development (thoughtco.com)

Kenrick, D.T. (2014, April 11). 7 Ways Facebook is Bad for Your Mental Health: How Staying In Touch May Be Driving You Nuts. Psychology Today. Retrieved from 7 Ways Facebook Is Bad for Your Mental Health | Psychology Today

Landry, C. (2020, October 15). Your Friday Briefing: The Coronavirus Meets Smog Season in India. The New York Times. Retrieved from Your Friday Briefing - The New York Times (nytimes.com)

Lee, S. (2020, June 16). Sabah Student Stays Overnight in Tree to Get Better Internet Connection for Online University Exams. The Star. Retrieved from Sabah student stays overnight in tree to get better Internet connection for online university exams | The Star

Macionis, J.J. (2015). Sociology (15 ${ }^{\text {th }}$ ed.). Essex, England: Pearson Education Limited.

Malaysiakini. (2021, January 24). Suhakam: Government Must Prevent Dropouts among Vulnerable Communities. Retrieved from Malaysiakini - Suhakam: Govt must prevent dropouts among vulnerable communities

Malaysian Communications and Multimedia Commission. (2018). Internet Users Survey 2018: Statistical Brief Number Twenty-Three. Retrieved from Internet-Users-Survey2018.pdf (mcmc.gov.my)

Malaysian Wireless. (2020, June 22). Malaysian Student Climbs a Tree to Get Stable 3G Internet Connection - Commentary. Malaysian Wireless. Retrieved from Student Climbs a Tree to get Stable 3G Internet Connection - Commentary (malaysianwireless.com)

MAMPU (Malaysian Administrative Modernisation and Management Planning Unit). (2019). Bridging the Digital Divide. Retrieved from https://www.malaysia.gov.my/portal/subcategory/757

MDEC (Malaysia Digital Economy Corporation). (2019). Advancing the Nation's Digital Agenda. Retrieved from Digital Adoption | MDEC

MIT (Massachusetts Institute of Technology). (n.d.). What 126 Studies Say About Education Technology. Retrieved from What 126 studies say about education technology | MIT News | Massachusetts Institute of Technology 
Plumer, B. (2021, January 12). Covid-19 Took A Bite From U.S. Greenhouse Gas Emissions in 2020. The New York Times. Retrieved from Covid Took a Bite From U.S. Greenhouse Gas Emissions in 2020 - The New York Times (nytimes.com)

Raja, R. \& Nagasubramani, P.C. (2018). Impact of Modern Technology in Education. DOI: 10.21839/jaar. 2018.v3iS1.165

Schleicher, A. (2020). The Impact of Covid-19 on Education: Insights from Education At A Glance 2020. Retrieved from the-impact-of-covid-19-on-education-insights-educationat-a-glance-2020.pdf (oecd.org)

Schwab, K. (2016). The Fourth Industrial Revolution. Geneva, Switzerland: World Economic Forum. Retrieved from (13) (PDF) The Fourth Industrial Revolution Klaus Schwab | animeid mg - Academia.edu

Shampa Iftakhar. (2016). Google Classroom: What Works and How? Journal of Education and Social Sciences, 3 (February), 12-18.

Tan, M.Z. (2020, June 25). Sabah Student Who Sat for Online Exams in Tree Gets Scholarship Offer, MCMC to Build Telco Tower Near Her Village. MalayMail. Retrieved from Sabah student who sat for online exams in tree gets scholarship offer, MCMC to build telco tower near her village | Life | Malay Mail

The Star. (2021, February 11). PdPR: Laptop Stocks Run Out in Most Stores. Retrieved from PdPR: laptop stocks run out in most stores | The Star

The Star. (2021, February 25). Moody's Analytics: MCO 2.0 Will Impact Malaysia's Economic Growth This Year. Retrieved from Moody's Analytics: MCO 2.0 will impact Malaysia's economic growth this year | The Star

Thompson, J. (2019, November 19). New Study Reveals Facebook's Impact on Mental Health. Parentology. Retrieved from New Study Reveals Facebook's Impact on Mental Health - Parentology

WHO (World Health Organization). (2021, February 25). WHO Coronavirus Disease (COVID-19) Dashboard. Retrieved from WHO Coronavirus Disease (COVID-19) Dashboard | WHO Coronavirus Disease (COVID-19) Dashboard 